\title{
EFFECT OF DEPROTEINIZATION AND TUBULAR OCCLUSION ON MICROTENSILE BOND STRENGTH AND MARGINAL MICROLEAKAGE OF RESIN COMPOSITE RESTORATIONS
}

\author{
Wagner BASEGGIO ${ }^{1}$, Elaine Cristina CONSOLMAGNO ${ }^{2}$, Flávia Lunardelli Negreiros de CARVALHO ${ }^{2}$, Julio Katuhide UEDA ${ }^{3}$, \\ Vera Lucia SCHMITT ${ }^{3}$, Luis Alberto FORMIGHIERI ${ }^{3}$, Fabiana Scarparo NAUFEL ${ }^{3}$
}

\author{
1- DDS, MSc, PhD Student, Department of Operative Dentistry, Endodontics and Dental Materials of Bauru School of Dentistry, University of São \\ Paulo, Bauru, São Paulo, Brazil. \\ 2- Undergraduate Student, Bauru School of Dentistry, University of São Paulo, São Paulo, Brazil. \\ 3- DDS, MSc, PhD, Department of Restorative Dentistry, UNIOESTE, Cascavel, Paraná, Brazil.
}

Corresponding address: Wagner Baseggio - Al. Octávio Pinheiro Brisola, 9-75 - 17012-901 Bauru, SP - Brasil - Phone: +55-14-3235-8000 - e-mail: baseggio@usp.br

Received: August 12, 2008 - Modification: November 09, 2008 - Accepted: November 30, 2008

\begin{abstract}
$D$

entin adhesion procedure presents limitations, especially regarding to lifetime stability of formed hybrid layer. Alternative procedures have been studied in order to improve adhesion to dentin. Objective: The aim of this study was to evaluate in vitro the influence of deproteinization or dentin tubular occlusion, as well as the combination of both techniques, on microtensile bond strength ( $\mu \mathrm{TBS}$ ) and marginal microleakage of composite resin restorations. Material and Methods: Extracted erupted human third molars were randomly divided into 4 groups. Dentin surfaces were treated with one of the following procedures: (A) $35 \%$ phosphoric acid gel (PA) + adhesive system (AS); (B) PA $+10 \% \mathrm{NaOCl}+\mathrm{AS}$; (C) PA + oxalate + $\mathrm{AS}$ and (D) PA + oxalate $+10 \% \mathrm{NaOCl}+\mathrm{AS}$. Bond strength data were analyzed statistically by two-way ANOVA and Tukey's test. The microleakage scores were analyzed using Kruskal-Wallis and Mann-Whitney non-parametric tests. Significance level was set at 0.05 for all analyses. Results: $\mu$ TBS data presented statistically lower values for groups $\mathrm{D}$ and $\mathrm{B}$, ranking data as $\mathrm{A}>\mathrm{C}>\mathrm{B}>\mathrm{D}$. The use of oxalic acid resulted in microleakage reduction along the tooth/restoration interface, being significant when used alone. On the other hand, the use of $10 \% \mathrm{NaOCl}$ alone or in combination with oxalic acid, resulted in increased microleakage. Conclusions: Dentin deproteinization with $10 \% \mathrm{NaOCl}$ or in combination with oxalate significantly compromised both the adhesive bond strength and the microleakage at interface. Tubular occlusion prior to adhesive system application seems to be a useful technique to reduce marginal microleakage.
\end{abstract}

Key words: Adhesive dentin. Oxalates. Sodium hypochlorite.

\section{INTRODUCTION}

Hybrid layer formation, as a consequence of resin monomer penetration and impregnation in exposed dentin collagen, is a widely accepted effective method used to increase composite resin bond strength to dentin ${ }^{6}$. However, several factors influence the stability of this layer over time, such as (1) incomplete infiltration of adhesive system in all demineralized dentin depth, (2) degradation of exposed collagen fibers which were not impregnated, (3) permeability of some adhesive systems, (4) noneffective sealing of dentinal tubules, (5) inadequate polymerization of adhesive systems, (6) cytotoxicity of non-polymerized adhesive systems to pulp ${ }^{1}$ and (7) technique sensitivity in maintaining moist dentin ${ }^{3,4}$.

Some studies have reported that collagen fibers do not significantly contribute to bond strength, questioning their real role on resin adhesion and sealing efficiency ${ }^{5,15,16}$. Dissolution and removal of collagen fibers with sodium hypochlorite after acid conditioning has been used with the attempt to increase the stability of restorative interface. This technique is known as deproteinization as a way to minimize the hybridization technique sensitivity, producing a more durable adhesion to dentin substrate through its hydroxyapatite component ${ }^{5,15,16}$. Additionally, it could also prevent degradation of organic components over time, once dentin demineralization results in a collagen fibril structure without mineral support, making the dentin susceptible to any physical alteration.

Oxalic acid desensitizer consists of low concentrations of oxalic acid. This acid reacts with calcium ions, forming calcium oxalate, which are acid-resistant insoluble crystals ${ }^{12}$. 
Oxalate ions diffuse further down into dentinal tubules tracking calcium ions available for reaction. Thus, it is possible to integrate the use of those agents prior to adhesive systems, reducing dentin hydraulic conductance of the dentin previously exposed by acid conditioning ${ }^{7,10}$.

Once those techniques present a potential clinical applicability and may improve the adhesive interface, the objective of this study was to evaluate both techniques, either individually or combined, in relation to their effects on (1) microtensile bond strength ( $\mu$ TBS) and (2) marginal microleakage.

\section{MATERIAL AND METHODS}

Extracted erupted human third molars were stored for no longer than 1 week in $4^{\circ} \mathrm{C}$ phosphate-buffer saline solution containing few crystals of thymol. They were sectioned $1 \mathrm{~mm}$ below the dentinoenamel junction using a diamond saw, in order to separate crown and root. A second parallel section just below the deepest central groove was performed to produce a crown segment which was enamelfree and presented flat occlusal dentin surface. Crown pieces were used for adhesive strength test while root pieces were used for microleakage test (Figure 1).

Forty-two teeth were used in this study. For the $\mu$ TBS test, flat dentin surfaces were obtained from deep dentin areas of the crown, using a slow-speed diamond saw (Isomet, Buehler Ltd., Lake Bluff, IL, USA) under water cooling. The obtained surfaces were abraded with wet 180 -grit silicon carbide papers in order to create smear-layer prior to bonding.

For microleakage test, the roots received Class V cavities at the center of proximal surfaces, with occlusal and cervical margins in enamel, and the following dimensions: $2 \mathrm{~mm}$ gingival-occlusally, $3 \mathrm{~mm}$ buccolingually and $1.5 \mathrm{~mm}$ deep. Preparations were performed with a water-cooled high-speed diamond bur \#330 (KG Sorensen, Barueri, SP, Brazil). Used burs were replaced by new ones after each 5 preparations. Eighty specimens were prepared and randomly divided into 4 groups.

\section{Dentin treatment}

For both tests, the specimens were treated with one of the following procedures, which are summarized in Table 1.

\section{Treatment A}

Dentin was etched with $35 \%$ phosphoric acid gel (3M/ ESPE, St. Paul, MN, USA) for $20 \mathrm{~s}$, copiously washed with water, gently dried with a small cotton pellet applied on the surface for 4-6 s and immediately coated with the adhesive system Single Bond (3M/ESPE).

\section{Treatment B}

Dentin was etched with 35\% phosphoric acid gel (3M/ ESPE) for $20 \mathrm{~s}$, copiously washed with water, gently dried with air spray from a small syringe. Each dentin disk was immediately treated with $10 \% \mathrm{NaOCl}$ for $60 \mathrm{~s}$, washed with water, dried with a small cotton pellet applied on the surface for 4-6 $\mathrm{s}$ and immediately coated with the adhesive system Single Bond (3M/ESPE).

\section{Treatment C}

Dentin was etched with $35 \%$ phosphoric acid gel (3M/ ESPE) for $20 \mathrm{~s}$, copiously washed with water, gently dried with air spray from a small syringe. Each dentin disk was immediately treated with oxalate for $30 \mathrm{~s}$ (Bisblock, Bisco Inc., Schaumburg, IL, USA) using rubbing movements, washed with water, dried with a small cotton pellet applied on the surface for 4-6 s and immediately coated with the adhesive system Single Bond (3M/ESPE).

\section{Treatment D}

Dentin was etched with $35 \%$ phosphoric acid gel (3M/ ESPE) for $20 \mathrm{~s}$, copiously washed with water, gently dried

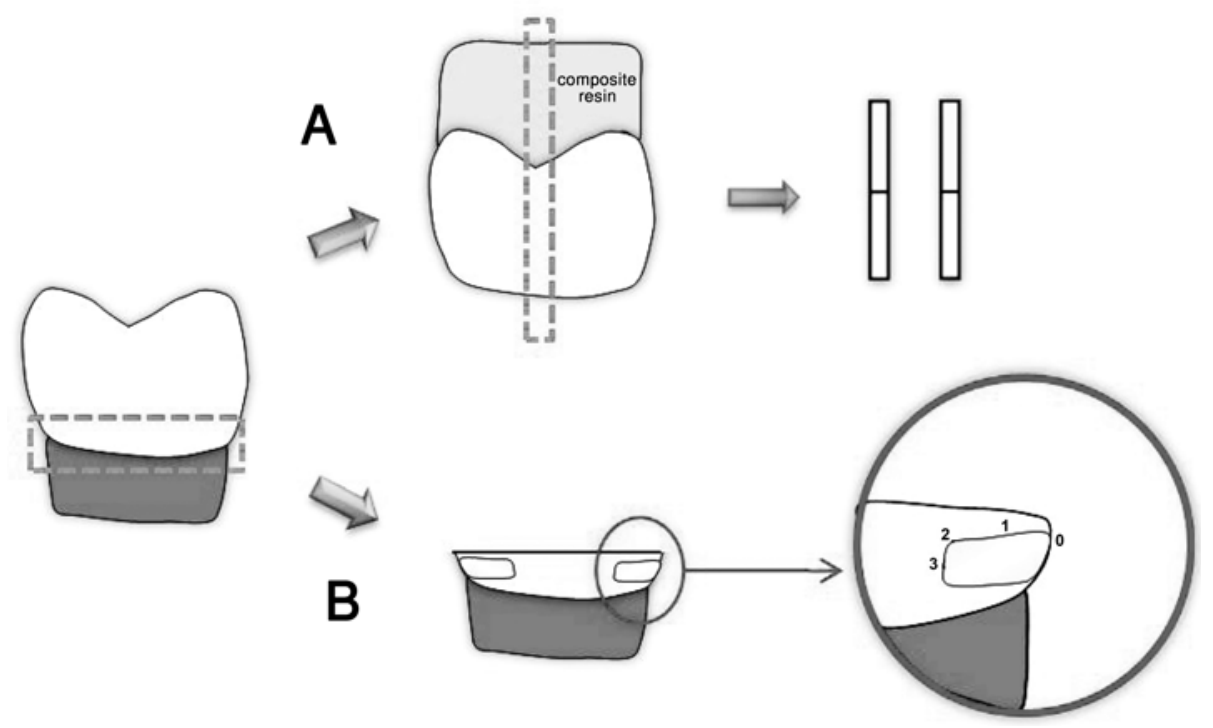

FIGURE 1- Summary diagram of test design (adapted from Sano, et al. 1995) 
TABLE 1- Dentin treatments used in this study

Treatment Description
A
B
$35 \% \mathrm{H}_{3} \mathrm{PO}_{4}, 20 \mathrm{~s}+$ adhesive + composite resin
C
$35 \% \mathrm{H}_{3} \mathrm{PO}_{4}, 20 \mathrm{~s}+10 \% \mathrm{NaOCl} 60 \mathrm{~s}+$ adhesive + composite resin
$\mathrm{D}$
$35 \% \mathrm{H}_{3} \mathrm{PO}_{4}, 20 \mathrm{~s}+$ oxalic acid $30 \mathrm{~s}+$ adhesive + composite resin
$35 \% \mathrm{H}_{3} \mathrm{PO}_{4}, 20 \mathrm{~s}+$ oxalic acid $30 \mathrm{~s}+10 \% \mathrm{NaOCl} 60 \mathrm{~s}+$ adhesive + composite resin

TABLE 2- Microtensile bond strength mean values and standard deviations

\begin{tabular}{cc}
\hline Treatment & ${\text { Mean }(M P a)^{\mathrm{a}}}$ \\
\hline A & $50.3812 \pm 3.4(42)^{\mathrm{A}}$ \\
B & $39.1584 \pm 2.6(40)^{\mathrm{B}}$ \\
C & $49.2964 \pm 5.0(42)^{\mathrm{A}}$ \\
D & $32.5917 \pm 4.2(38)^{\mathrm{C}}$ \\
\hline
\end{tabular}

Values are expressed as means \pm standard deviations. Number of tested specimens is in parenthesis. Experimental groups identified by different superscript letters are significantly different from the control group $(P<0.05)$.

with air spray from a small syringe. Each dentin disk was immediately treated firstly with oxalate for $30 \mathrm{~s}$ (Bisblock, Bisco Inc.) using rubbing movements and secondly with $10 \%$ $\mathrm{NaOCl}$ for $60 \mathrm{~s}$, washed with water, dried with a small cotton pellet applied on the surface for 4-6 s and immediately coated with the adhesive system Single Bond (3M/ESPE).

\section{$\mu$ TBS testing}

The area for adhesion on dentin was defined by a fenestrated clear film applied on dentin surface. The fenestration comprised of a circular hole of $3 \mathrm{~mm}$ in diameter. Composite buildups were performed with the use of a light-cured hybrid composite (Z100; 3M/ESPE) in five $1-\mathrm{mm}$ increments. Specimens were immersed in distilled water and stored for $24 \mathrm{~h}$ at $37^{\circ} \mathrm{C}$. The samples were sectioned occluso-gingivally into 0.9 -mm-thick serial slabs using Isomet saw under water-cooling. The slabs were further sectioned into $0.9 \times 0.9 \mathrm{~mm}$ composite-dentin beams, according to the "non-trimming" technique version of the $\mu$ TBS test, reported by Pashley, et al. ${ }^{7}$ (1999).

After examination under a stereomicroscope at 20x, beams containing peripheral enamel or imperfections were discarded, ranging 37-46 beams per group. Each beam was stressed to failure under tension in a universal testing machine (Model 4440; Instron Inc., Canton, MA, USA) at a crosshead speed of $1 \mathrm{~mm} / \mathrm{min}$. Bond strength data from the 4 experimental groups were analyzed statistically by twoway ANOVA on ranks (surface condition vs. material) with statistical significance set at 0.05. Post-hoc multiple comparisons of the experimental groups were performed by Tukey's test.

\section{Microleakage Evaluation}

Specimens were subjected to a thermocycling regimen (Instrumental MCT-2, São Paulo, SP, Brazil) of 500 cycles in water between $5^{\circ} \mathrm{C}-55^{\circ} \mathrm{C} \pm 2^{\circ} \mathrm{C}$, with a dwell time of $60 \mathrm{~s}$ in each bath. After thermocycling, all external surfaces of each tooth were coated with two layers of acid-resistant varnish, leaving $1 \mathrm{~mm}$-wide varnish-free margins around the restoration. The teeth were immersed into a $2 \%$ methylene blue buffer solution for $4 \mathrm{~h}$.

The teeth were then thoroughly rinsed under tap water for $10 \mathrm{~min}$. They were sectioned longitudinally at the center of the restoration with a slow-speed diamond disk (KG Sorensen, São Paulo, SP, Brazil). Two independent observers separately analyzed the margins under stereomicroscope magnification at $20 \mathrm{x}$ to determine dye penetration. The following criteria were used to score dye penetration: $0=$ no dye penetration, $1=$ dye penetration up to half depth of restoration, 2 = dye penetration deeper than half depth of the restoration, but not reaching axial wall, $3=$ dye penetration reaching axial wall or further. The scores for each group were analyzed using Kruskal-Wallis and MannWhitney non-parametric tests with statistical significance level set at 0.05 .

\section{RESULTS}

\section{$\mu$ TBS}

$\mu$ TBS results from the 4 different treatments are summarized in Table 2. The combination of deproteinization and tubular occlusion resulted in a significant reduction of MBS in comparison with the conventional treatment $(35 \%$ phosphoric acid and adhesive in dentin) $(\mathrm{p}<0.05)$. Dentin treatment with $35 \% \mathrm{H}_{3} \mathrm{PO}_{4} 20 \mathrm{~s}+$ oxalic acid $30 \mathrm{~s}+10 \%$ $\mathrm{NaOCl} 60 \mathrm{~s}+$ adhesive resulted in the lowest bond strength, being statistically significantly. However, when dentin was treated with $35 \% \mathrm{H}_{3} \mathrm{PO}_{4}, 20 \mathrm{~s}+$ oxalic acid $30 \mathrm{~s}+$ adhesive, the obtained bond strength values were unaffected, presenting no statistical differences in comparison to the conventional technique ( $35 \% \mathrm{H}_{3} \mathrm{PO}_{4}, 20 \mathrm{~s}+$ adhesive).

\section{Marginal Microleakage Test}

Dentin deproteinization with $10 \% \mathrm{NaOCl}$ for $60 \mathrm{~s}$ significantly increased microleakage at dentin margins $(\mathrm{p}=$ $0.0012)$. The combination of deproteinization and dentin tubules occlusion $\left(35 \% \mathrm{H}_{3} \mathrm{PO}_{4}, 20 \mathrm{~s}+\right.$ oxalic acid $30 \mathrm{~s}+$ $10 \% \mathrm{NaOCl} 60 \mathrm{~s}+$ adhesive) also increased the microleakage 
TABLE 3- Distribution of microleakage scores according to treatment

Treatment

Scores

\begin{tabular}{rrrrr} 
& $\mathbf{0}$ & $\mathbf{1}$ & $\mathbf{2}$ & \multicolumn{1}{c}{$\mathbf{3}$} \\
\hline A & 0 & 0 & 8 & 12 \\
B & 0 & 0 & 4 & 16 \\
C & 0 & 4 & 8 & 8 \\
D & 0 & 0 & 10 & 10 \\
\hline
\end{tabular}

at dentin margins. The use of only oxalic acid reduced microleakage along the tooth/restoration interface (Table 3).

\section{DISCUSSION}

Enamel treatment with phosphoric acid is a widely well accepted procedure used to increase adhesion between substrate and composite resin ${ }^{17}$. However, bonding to dentin remains a challenge. Pursuing stable dentin adhesion is difficult due to its complex structure and biological activity, making the diffusion of adhesive resin throughout dentin collagen layer a sensitive procedure ${ }^{1,14}$.

Failure of adhesive penetration leads to unprotected collagen fibers. Those unprotected fibers when exposed to oral environment are submitted to hydrolysis after long-term exposure to water, promoting adhesion deterioration by means of nanoleakage ${ }^{4,11}$.

The real role of collagen fibers in dentin adhesion is questioned. Some authors report that dentin collagen does not contribute to dentin adhesion and might even interfere with bonding mechanisms, mainly due to the presence of fragile structured collagen fibers after acid etching ${ }^{5,15,16}$.

However, the results of this study showed that $10 \%$ $\mathrm{NaOCl}$ adversely affected adhesive strength. Dentin surfaces were firstly decalcified, exposing collagen fibers, which were afterwards removed with the use of hypochlorite. The negative effect on adhesive strength may be due to the utilization of an adhesive containing alcohol as a solvent. As this type of adhesive system self-spreads slower than acetone-based ones, the time frame recommended by the manufacturer for its application could have been insufficient to allow full dissemination of monomers into the substrate. Thus, nanometric pores created by $\mathrm{NaOCl}$ remain within intertubular dentin and are not properly infused by resin monomer, creating a deficient adhesive interface. That might explain the lower values of bond strength obtained with this treatment, when compared to adhesive systems containing acetone as a solvent, which is in agreement with other studies reported in the literature ${ }^{8,9,13}$. Acetone presents different ability for water displacement and consequent diffusion into the substrate. The higher diffusion ability of acetone-based adhesive improves monomer contact with the irregular intertubular structure of dentin exposed by $\mathrm{NaOCl}$ treatment.
It is also hypothesized that collagen fibers layer presents a more important role on bond strength than adhesive resin tags formed within dentinal tubules ${ }^{16}$. This could explain the similar values of bond strength for both the control and the oxalic acid treated groups in this study. Once tubular occlusion with calcium oxalate crystals occurs at the subsurface, the morphological difference at the adhesive interface may be expressed by formation of very short tags. However, it is believed that only the first 2 to $3 \mu \mathrm{m}$ of a resin tag have some relevance in bond strength. This tag length seems to be sufficient since the adhesion to peritubular dentin walls exceeds the cohesive strength of the tags, suggesting that longer tag formation might be unnecessary ${ }^{3}$. Confirming this information, the results of bond strength were not affected, even though the possible tubular occlusion caused by oxalic acid (Treatment $\mathrm{C}$ ) might have prevented the formation of long resin tags.

Oxalic acid diffused through the demineralized dentin tracking deeper mineralized intertubular and peritubular dentin matrices. At this mineralized area, sufficient amount of calcium was solubilized to form insoluble subsurface crystals of calcium oxalate within the tubules, as described by Pashley, et $\mathrm{al}^{7}$. (2001). As those crystals were found to reduce the hydraulic conductance of dentin ${ }^{2}$, it would limit osmotically induced water movement during bonding procedures. This reduction in dentinal fluids promotes better humidity control during the application of adhesive system over dentin surface, leading to an adhesive interface with less water incorporation and lower rates of nanoleakage $e^{7,10}$. Once it was reported that this treatment does not affect bond strength, the adjunctive use of oxalate desensitizers following dentin acid-etching is a viable means of reducing dentinal fluid transudation in total-etch bonding procedures, bringing benefits to the durability of adhesion.

However, when tubular occlusion is used in conjunction with deproteinization procedures (Treatment D), a significant reduction in bond resistance is observed, corroborating with literature data that collagen removal can be beneficial for some adhesive systems but not for others.

The use of $10 \% \mathrm{NaOCl}$ increased the microleakage of composite resin restorations when using water-based adhesive. This is probably related to the deficient adhesive interface formed. When tubular occlusion was performed, this treatment favored the reduction of marginal microleakage, possibly due to the formation of oxalate crystals formation. When deproteinization was associated with tubular occlusion (Treatment D), the possible negative effect of deproteinization for the adhesive interface using water-based adhesive is reinforced in part by the tubular occlusion promoted by oxalic acid.

\section{CONCLUSION}

According to the results obtained in this study, collagen removal adversely affected bond strength of adhesive interface and marginal microleakage of composite resin restorations, when water-based adhesive systems were 
employed. The integrity of left exposed collagen fibers upon acid-etching played an important role on adhesion mechanism of the tested adhesive systems. Tubular occlusion seems to be a useful technique to reduce marginal microleakage, with no interference on the $\mu \mathrm{TBS}$.

\section{REFERENCES}

1- Cadenaro M, Breschi L, Antoniolli F, Navarra CO, Mazzoni A, Tay FR, et al. Degree of conversion of resin blends in relation to ethanol content and hydrophilicity. Dent Mater. 2008;24(9):1194-200.

2- Camps J, Pizant S, Dejou J, Franquin JC. Effects of desensitizing agents on human dentin permeability. Am J Dent. 1998;11:286-90.

3- Carrilho MR, Tay FR, Sword J, Donnelly AM, Agee KA, Nishitani Y, et al. Dentine sealing provided by smear layer/smear plugs vs. adhesive resins/resin tags. Eur J Oral Sci. 2007;115(4):321-9.

4- Carrilho MR, Tay FR, Donnelly AM, Agee KA, Carvalho RM, Hosaka $\mathrm{K}$, et al. Membrane permeability properties of dental adhesive films. J Biomed Mater Res B Appl Biomater. 2009;88(2)312-20.

5- Erhardt MC, Osorio E, Aguilera FS, Proença JP, Osorio R, Toledano $\mathrm{M}$. Influence of dentin acid-etching and $\mathrm{NaOCl}$-treatment on bond strengths of self-etch adhesives. Am J Dent. 2008;21(1):44-8.

6- Nakabayashi N, Kojima K, Masuhara E. The promotion of adhesion by the infiltration of monomers into tooth substrates. J Biomed Mater Res. 1982;16(3):265-73

7- Pashley DH, Carvalho RM, Pereira JC, Villanueva R, Tay FR. The use of oxalate to reduce dentin permeability under adhesive restorations. Am J Dent. 2001;14(2):89-94.

8- Perdigão J, Lopes M, Geraldeli S, Lopes GC, García-Godoy F. Effect of a sodium hypochlorite gel on dentin bonding. Dent Mater. 2000;16(5):311-23

9- Pimenta LA, Amaral CM, Bedran de Castro AK, Ritter AV. Stability of dentin bond strengths using different bonding techniques after 12 months: total-etch, deproteinization and self-etching. Oper Dent. 2004;29(5):592-

10- Sadek FT, Pashley DH, Ferrari M, Tay FR. Tubular occlusion optimizes bonding of hydrophobic resins to dentin. J Dent Res. 2007; 86(6):524-8

11- Sano H, Takatsu T, Ciucchi B, Horner JA, Matthews WG, Pashley DH. Nanoleakage: leakage within the hybrid layer. Oper Dent $1995 ; 20(1): 18-25$.

12- Silva SMA, Marquezini L Jr, Manso AP, Garcia FP, Carrilho MR, Pashley DH, et al. Effects of a combined application of potassium oxalate gel/adhesive agent on dentin permeability in vitro. J Adhes Dent. 2007;9(6):505-12.

13- Souza FB, Silva CH, Dibb RGP, Delfino CS, Souza Beatrice LC Bonding performance of different adhesive systems to proteinized dentin microtensile bond strength and scanning electron microscopy. J Biomed Mater Res B Appl Biomater. 2005;75(1):158-67.

14- Tay FR, Hashimoto M, Pashley DH, Peters MC, Lai SC, Yiu CK, et al. Water movement in the hybrid layer after different dentin treatments. Dent Mater. 2004;20(9):796-803.

15- Toledano M, Perdigão J, Osório R, Osório E. Effect of dentin deproteinization on microleakage of Class $\mathrm{V}$ composite restorations. Oper Dent. 2000;25(6):497-504
16- Toledano M, Perdigão J, Osorio E, Osorio R. Influence of $\mathrm{NaOCl}$ deproteinization on shear bond strength in function of dentin depth. Am J Dent. 2002;15(4):252-5.

17- Van Meerbeek B, De Munck J, Yoshida Y, Inoue S, Vargas M, Vijay P, et al. Buonocore memorial lecture: adhesion to enamel and dentin: current status and future challenges. Oper Dent. 2003;28(3):215-35. 